\title{
O túnel no fim da luz: a privatização do setor elétrico em Mato Grosso
}

\author{
Vinícius de Carvalho Araújo*
}

\section{Introdução}

Este artigo é o resumo da monografia submetida ao XVII Concurso de Monografias do Centro Latino-Americano para el Desarollo (CLAD), realizado todos os anos por este organismo, sediado em Caracas, que desempenha papel fundamental na área de gestão pública em países iberoamericanos. Essa monografia foi premiada com menção honrosa, cujo objetivo principal é exposto nesta oportunidade.

O tema sugerido pelo CLAD para o concurso de 2003 foi a formação de consensos sociais e políticos para a reforma do Estado e de seu aparelho na América Latina. Adotou-se uma problematização que enfocou a privatização da companhia de energia elétrica do Estado de Mato Grosso, as Centrais Elétricas Mato-Grossenses (Cemat), pelas possibilidades analíticas sobre a dinâmica da reforma em nível subnacional, pouco explorada pela literatura.

Revisou-se, portanto, o referencial metodológico composto pelo problema da pesquisa e pelas suas hipóteses de trabalho, as quais pretendem orientá-lo no relato de seus resultados e no alcance do objetivo geral, que é identificar a coalizão social e política que tornou possível ao Poder Executivo estadual promover essa reforma, conforme a governabilidade democrática descrita em trabalhos anteriores (ARAúJo, 2002, 2003). Para isso, o trabalho foi dividido em quatro partes principais.

$\mathrm{Na}$ primeira, apresenta-se a metodologia adotada na pesquisa, com ênfase na modalidade "estudo de caso" da espécie "provas de plausibilidade", que se revela adequada para o objeto em questão. Na segunda, faz-se breve retrospectiva da situação do setor elétrico, com destaque para a sua
Vinícius de

Carvalho

Araújo é gestor governamental da Secretaria de

Planejamento e

Coordenação

Geral (Seplan)

do Estado de

Mato Grosso e

especialista em

Políticas e

Estratégias para o Setor Público pela

Universidade

Federal do

Mato Grosso.

Contato:

vcaraujo@ terra.com.br 
formação e a crise que vem atravessando desde a década de 1980. Na terceira, descrevem-se os passos da privatização da Cemat e apontam-se os recursos utilizados para a formação do apoio necessário. Por fim, na última parte, apresentam-se considerações finais relacionadas à validade das hipóteses definidas a princípio.

\section{Metodologia}

Este trabalho constitui uma pesquisa exploratória e, conforme seu delineamento, um estudo de caso. Tal modalidade está adequada aos seus objetivos em razão da incipiência em que se encontram a maior parte dos trabalhos, a simplicidade dos procedimentos técnicos, a complexidade do tema selecionado e da possibilidade de reformulação do problema e de suas hipóteses, em busca de maior depuração analítica, conforme descrição a seguir.

A escolha da privatização da empresa Cemat para análise, neste trabalho, entre várias organizações incluídas no Programa de Reforma do Estado em Mato Grosso, conforme se verá, decorre de alguns pontos importantes.

1) De todas as sociedades de economia mista ou empresas públicas de propriedade do Estado de Mato Grosso, a única que conseguiu ser privatizada foi a Cemat, por tratar-se de serviço público cujo fornecimento não pode ser interrompido e do qual o Estado sai da condição de produtor para regulador, mudando-se sua posição no aspecto qualitativo. As demais ou não tiveram condições financeiras e patrimoniais para a privatização, ou exerciam funções típicas de Estado pelas quais o setor privado pouco se interessava ou cujo marco regulatório estivesse pouco definido em nível nacional.

2) Como a liquidação de organizações dessa natureza é lenta, tortuosa e de difícil compreensão para profissionais que não são do meio jurídico, contábil e econômico-financeiro, preferiu-se a privatização pelo seu caráter mais completo - contém início, meio e fim - e "clássico", pela sua articulação com a política macroeconômica em curso e pela formação de base referencial-comparativa importante para observação de outros casos nacionais e internacionais.

3) O setor elétrico, entre os modais de infra-estrutura e os serviços públicos com predominância estatal até 1995 - telecomunicações, transportes, saneamento -, possui características específicas, que tornaram a sua re-regulamentação no contexto da reforma do Estado e de seu aparelho objeto interessante para análise, como a distribuição de competências entre as unidades da Federação e a estrutura de propriedade fragmentada. Ainda não há modelo aceito, e o relacionamento entre os agentes novos, 
como o Operador Nacional do Sistema Elétrico (ONS), o Mercado Ata-

cadista de Energia Elétrica (MAE) e a Agência Nacional de Energia Elétrica (Aneel), e os velhos, como as Centrais Elétricas Brasileiras (Eletrobrás) e suas subsidiárias, o Ministério das Minas e Energia e o Conselho Nacional de Política Energética, revelou-se confuso e crivado de conflitos, levados ao conhecimento do grande público na fratura exposta do racionamento de 2001-2002.

Segundo Rhodes (1997), embora os estudos de caso sejam excessivos em algumas áreas, como História e Administração, e muito criticados por se concentrarem no único e particular, eles são capazes de comparar e generalizar, desde que sejam feitas algumas ressalvas metodológicas. Eckstein promoveu uma discussão, nos anos de 1970, sobre os estudos de caso em Ciência Política e apresentou a seguinte tipologia, ou gênero, composta por cinco espécies, a saber:

- configurativo-ideográfico: descrição de objetos específicos;

- disciplinar-configurativo: aplicação de leis gerais a objetos específicos;

- heurísticos: construção de teoria ao identificar problemas gerais e possibilidades teóricas de solução;

- provas de plausibilidade: conduzidos como testes preliminares de hipóteses para verificação da sua validade;

- cruciais: experimentos decisivos.

Na sequiência, Rhodes relembra que os estudos de caso não são apenas descritivos, como muitos afirmam. "Eles podem e de fato permitem generalizações. Eles constituem uma alternativa aos métodos quantitativos, não uma relação pobre" (RHODEs, 1997, p. 82). Ou seja, os estudos de caso são capazes de combinar as "questões - o quê" dos historiadores, que preferem narrações, com as "questões - por quê" dos cientistas políticos, mais suscetíveis às dissertações. A solução plausível para esse problema está na mescla da descrição e da análise.

Depois dessa contextualização, pode-se detalhar mais os aspectos metodológicos deste trabalho. Como já foi dito, este é um estudo de caso sobre a privatização da empresa de energia elétrica de propriedade do Estado de Mato Grosso e seu objetivo geral é identificar a coalizão social e política que tornou possível ao Poder Executivo estadual promover tal reforma, conforme a governabilidade democrática descrita em trabalhos anteriores (ARAúJo, 2002, 2003).

Trata-se, conforme a tipologia de Eckstein, de estudo de caso da espécie "provas de plausibilidade". Formulou-se um referencial metodológico inicial composto pelo problema da pesquisa e pelas hipóteses de trabalho que pretendem orientá-lo. Por meio da aplicação interativa reiterada, continuada - proposta por Yin, apud Rhodes (1997), é feita uma proposição teórica inicial e as conclusões da pesquisa são comparadas 
com ela, o que permite sua revisão e a comparação com outros detalhes. Em seguida, repete-se esse procedimento até que a proposição aproxime-se da realidade empírica em que está sendo analisada, numa analogia com o método das aproximações sucessivas usado em estudos sócioeconômicos, para que se possa chegar a conclusões com maior capacidade de generalização pela submissão aos testes.

Neste trabalho, limitar-se-á apenas à uma "primeira aproximação" sob esse enquadramento. Não se fará análise comparativa completa com processos congêneres ocorridos em outros estados brasileiros por limitações operacionais da própria pesquisa, mas, ao se testarem as variáveis críticas que contribuíram para a formação da coalizão social e política para a privatização da Cemat, apresentadas nas hipóteses de trabalho, será feita a verificação de sua existência em outros casos para validar a eficácia explicativa.

Com base nessas explicações iniciais, o problema de pesquisa será enunciado da seguinte forma: quais foram as variáveis críticas para a formação da coalizão social e política que viabilizou a privatização da Cemat, na perspectiva da governabilidade democrática?

Para responder a essa pergunta, são apresentadas quatro hipóteses de trabalho, baseadas na compreensão teórico-conceitual detalhada em trabalhos anteriores (ARAúJo, 2002; 2003) sobre as dimensões da governabilidade/governança, que enfatiza tanto os aspectos substantivos e materiais da autoridade política do Estado e sua legitimidade diante da cidadania (hipóteses 3 e 4) quanto os adjetivos e instrumentais (hipóteses 1 e 2).

Hipótese 1 - A situação do setor elétrico no Brasil e alguns indicadores relativos à Cemat (estrutura desverticalizada, funcionários, indicadores operacionais e financeiros, passivo, localização, dimensão) contribuíram para a privatização.

Hipótese 2 - A situação orçamentária, financeira e patrimonial do Estado de Mato Grosso estava deteriorada.

Hipótese 3 - A formação de uma coalizão nacional voltada para a reforma do Estado e de seu aparelho adotada a partir de 1995 contribuiu para o avanço desse processo em nível estadual.

Hipótese 4-A dinâmica político-institucional dos estados brasileiros e o seu posicionamento no contexto federativo influenciaram o processo decisório relativo às políticas de reforma e ajustamento estrutural em Mato Grosso.

\section{Retrospectiva histórica do setor elétrico}

Com a crise em que mergulhou a economia brasileira durante a década de 1980, o setor elétrico sofreu um processo acelerado de sucateamento e "financerização", pois as receitas tarifárias reais, os 
aportes financeiros dos seus controladores e os investimentos caíram e, para manter um padrão mínimo de atividade, as companhias passaram a recorrer a empréstimos e financiamentos, muitas vezes dolarizados. É prudente lembrar também que o baixo crescimento da economia nesse período - em especial da indústria - não pressionou o setor pelo aumento de capacidade.

Conforme Ferreira (1999), em 1985, 60\% da receita agregada do setor provinham dessa fonte (com apenas $25 \%$ para tarifas) e, em 1989 , 98\% das despesas foram utilizados para pagamento do serviço da dívida. Algumas companhias, em 1995, como a Companhia Energética de Alagoas (Ceal), chegavam a uma relação passivo/ativo de mais $30 \%$ e a dívida acumulada do setor totalizava US\$ 25 bilhões ( $\mathrm{R} \$ 48,549$ bilhões, em 2003). A Cemat não estava mal nesse aspecto, pois sua relação passivo/ ativo era de 11,22\% em 1995.

É nesse quadro de baixos investimentos, de elevado comprometimento da receita para o serviço da dívida, de ameaça de colapso no abastecimento energético no país e de redefinição do papel do Estado na produção que as elites começaram a discutir novo marco regulatório para o setor elétrico. Em 1993, em meio à crise desse setor, a Lei no 8.631 inicia a privatização do ponto de vista técnico, ao eliminar o nivelamento de tarifas e sua diferenciação em suprimento para as geradoras e fornecimento para as distribuidoras. O Presidente Itamar Franco, por seu apoio reticente ao Programa Nacional de Desestatização, recusou-se a autorizar ao setor reajustes iguais à inflação para, supostamente, beneficiar a população.

Entretanto, a inclusão do setor elétrico na lista dos privatizáveis e a montagem de novo marco regulatório com essa orientação ganham fôlego apenas a partir de 1995, no contexto da eleição de Fernando Henrique Cardoso e dos efeitos do Plano Real sobre o ultrapresidencialismo estadual, conforme Abrúcio (2000).

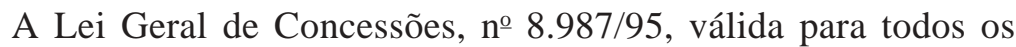
serviços públicos, regulamentou a Constituição Federal e exigiu licitações baseadas no equilíbrio econômico-financeiro das companhias, o que abriu caminho para a reestruturação e a privatização do setor elétrico. Em seguida, a Lei no 9.074 estende para 20 anos o prazo de conclusão das usinas paradas, com a apresentação de um plano por estas que contemplasse a participação de, pelo menos, 1/3 de capital privado. Outra mudança importante trazida por essa lei foi o conceito de produtores independentes, que poderiam atender consumidores livres.

Nesse período, o debate no interior do aparelho do Estado polarizouse em duas posições. A primeira reunia atores, como a Eletrobrás e suas subsidiárias, companhias estaduais, algumas frações da burguesia industrial e forças políticas à esquerda, que preconizavam a manutenção do setor 
elétrico como estatal e o não-desmembramento das companhias verticalizadas para dificultar a desestatização, caso esta se revelasse inevitável.

A segunda propunha a privatização imediata e depois a formação de ambiente competitivo com a desverticalização das companhias, ou seja, a conversão do monopólio estatal em monopólio privado. Essa posição derivava, além da preferência ideológica pela produtividade superior do setor privado, típica do neoliberalismo, de defesa por maior participação do empresariado brasileiro na aquisição das companhias em função da sobrevalorização cambial (a cotação do dólar flutuava, nesse período, na faixa de $\mathrm{R} \$ 0,86$ a $\mathrm{R} \$ 0,99)$, o que encareceria seu valor para investidores estrangeiros e constituiria reserva de mercado. Na ocasião, todos sabiam do caráter efêmero da âncora cambial e que, com uma eventual desvalorização do real, o valor de compra em dólar cairia muito, ampliando a presença internacional.

Nesse ponto, convém salientar algumas características do processo decisório no Brasil. Um dos traços marcantes do aparelho do Estado, em especial na União, é a autonomização de determinados setores em relação ao centro de poder político-administrativo, ou o spoils system (regime de espólio), muito citado pelos autores norte-americanos. Pela articulação direta com setores do capital, pela influência de oligarquias regionais ou partidárias ou mesmo pelo aparelhamento de determinados estratos mais privilegiados da burocracia, para formular políticas com prazo longo e sem "influência externa", existem determinados setores quase impermeáveis à função de coordenação, constituindo os famosos "Estados paralelos".

Segundo Martins (1995), uma das deficiências estruturais engendradas pelo Decreto-Lei n-200/67 foi o relacionamento difícil e conflitante entre a administração direta e a indireta. A ausência de regras claras, expressas em contratos de gestão, como na Europa, para disciplinar a relação do Poder Executivo e o setor paraestatal, foi foco de tensão permanente. Quando representantes das agências centrais ou mesmo dos ministérios setoriais eram indicados para disciplinar as companhias, os integrantes destas os sabotavam ou os forçavam a aceitar sua lógica, tornando-se refratárias a qualquer tipo de intervenção.

Pois bem, assim também ocorreu com a Eletrobrás. Além de ter presença muito grande de aliados do atual Senador Antônio Carlos Magalhães - que foi seu presidente durante o período de "ouro" (o mandato do General Geisel) - e de seu partido, o PFL, a Eletrobrás e suas subsidiárias desenvolveram uma burocracia articulada com setores do empresariado e com as distribuidoras estaduais, de acordo com a conformação adquirida pelo sistema elétrico no Brasil.

Uma das principais marcas do estilo de gestão adotado pelo Presidente Fernando Henrique foi o fortalecimento da capacidade de coordenação e o insulamento da Presidência da República e de algumas agências 
centrais e setoriais, destinadas a integrantes da "ala tecnocrática" do

PSDB. Aqui entram os Ministérios da Fazenda, com destaque para as Secretarias da Receita Federal e do Tesouro Nacional, e do Planejamento, a Casa Civil, o Banco Central, o BNDES e alguns ministérios setoriais considerados prioritários, como Saúde, Educação, Comunicações, Reforma Agrária e Relações Exteriores. Por meio desse mecanismo, o presidente ampliou seu raio de influência e conseguiu controlar mais a distribuição de cargos na coalizão e as próprias políticas públicas.

Contudo, como a aliança era muito ampla e um dos meios tradicionais para a formação de maiorias no Parlamento é a distribuição de cargos nos ministérios e na administração indireta, o presidente destinou determinados setores a partidos aliados. Devido à força do Senador Antônio Carlos Magalhães, que presidiu o Senado entre 1997 e 2001 e foi um dos sustentáculos da bancada de apoio ao presidente no Parlamento, alguns ministérios foram destinados ao PFL, como Previdência, Meio Ambiente e Minas e Energia. Essa divisão acabou prejudicando a capacidade de coordenação presidencial no setor elétrico e trouxe alguns efeitos importantes.

A primeira coalizão fica restrita, portanto, ao setor elétrico e a segunda é composta pela equipe montada para a condução do plano de estabilização, em especial no que se refere às políticas macroeconômicas necessárias para a sua manutenção monetária, cambial e fiscal. O padrão de relacionamento dessa equipe com as políticas setoriais acabou determinando, em muitos casos, o rumo tomado por elas e por seus formuladores ao longo dos dois mandatos do Presidente Fernando Henrique Cardoso, como foi o caso do Ministério da Administração Federal e Reforma do Estado.

Podemos dizer, numa perspectiva própria de análise da política pública, que o contexto da política energética no Brasil, no período em questão, revelou-se complexo e confuso, dificultando, no sentido gramsciano, a formação de coalizão ou "bloco hegemônico" que pudesse optar por orientação estratégica para o setor e sustentá-la ao longo do tempo. As coalizões conviveram, demarcaram território, reconheceram-se e traçaram caminhos com autonomia relativa, o que acabou condicionando a formação de agenda híbrida. Ou seja, as duas coalizões protegeram-se e celebraram algumas alianças táticas nos pontos convergentes, que prejudicaram, como foi dito, o surgimento de orientação estratégica - a ausência de planejamento nesse nível e de lei geral é sintomática - que pudesse orientar a evolução do setor a médio e longo prazo. Isto ocorreu porque a primeira estava relacionada à Eletrobrás e possuía uma visão que refletia a estratégia empresarial dessa companhia em relação ao setor e a segunda tinha como objetivo a consolidação do plano de estabilização e não atentava, de forma específica, para aspectos setoriais. 
Essa dicotomia acabaria revelando-se danosa, pois elementos que deveriam ter tratamento sistêmico, porque têm efeitos sinérgicos, foram trabalhados separadamente, o que, somado a outros fatores, provocou o racionamento de 2001-2002, desnudando-se, assim, os problemas dessas coalizões ao grande público. Para muitos analistas, o grande erro do Presidente Fernando Henrique foi não se ter envolvido pessoalmente nessa disputa e arbitrado essa disputa, optando por uma das alternativas ou por uma combinação negociada, mas consistente, de ambas, com a indicação de alguém com perfil técnico - um gerente profissional alheio ao setor próximo a ele que pudesse conduzir o processo de forma semelhante ao realizado pelo Ministro Sérgio Motta nas telecomunicações.

No início de 1996, a Eletrobrás contratou uma consultoria norteamericana chamada Coopers \& Lybrand para deslocar o debate dos pólos privatização e estatização e apresentar novo marco regulatório para o setor, contendo um regime de transição. O desafio posto para a consultoria era projetar um modelo descentralizado e funcional, não obstante a propriedade das companhias. Tal modelo teve tanta influência nos policymakers do setor que acabou sendo incorporado a ele pela Lei $n^{-}$ 9.648, de maio de 1998, que também autorizou a reestruturação das subsidiárias da Eletrobrás.

As principais características desse modelo proposto foram:

1) criação do MAE para estabelecer o preço de referência nos contratos bilaterais e administrar o mercado à vista;

2) definição de "contratos iniciais" para pautar o regime de transição para ambiente competitivo;

3) desmembramento dos ativos de transmissão e a criação de operador independente do sistema interligado (para cumprir as funções do sistema centralizado de despacho);

4) criação de agência independente de planejamento indicativo, denominada Instituto de Desenvolvimento do Setor Elétrico, para estudo de capacidades hidrológicas e ambientais;

5) manutenção da Eletrobrás como agente financeiro do setor.

Para que a desestatização pudesse caminhar, ainda que de forma restrita, foi necessária a criação da Aneel pela Lei no 9.427/96 e a inclusão de cláusulas indexando os futuros reajustes tarifários aos índices de inflação - o denominado teto de preço -, de forma que os investidores tivessem alguma segurança na aquisição das companhias, independente do marco regulatório do setor. É importante salientar que a Aneel foi autorizada a dividir tarefas com agências estaduais de regulação por meio de convênios específicos, como foi o caso da Comissão Estadual de Serviços de Energia em São Paulo e da Agência Estadual de Regulação dos Serviços Públicos do Estado de Mato Grosso (Ager/ MT). Passemos agora ao caso Cemat. 


\section{Descrição da privatização}

De acordo com as características do Estado de Mato Grosso e a evolução do setor elétrico descritas anteriormente, pode-se situar o leitor no processo que resultou na privatização da Cemat. A exemplo de suas congêneres, a Cemat vinha atravessando situação delicada desde, pelo menos, o início da década de 1990, quando o setor enfrentou a sua crise mais grave.

Embora o crescimento médio do mercado nos seis anos anteriores à privatização tenha sido de $10 \%$, a Cemat era uma das piores companhias estaduais do setor elétrico, de acordo com seus indicadores operacionais e financeiros. Basta dizer que as perdas de cerca de $\mathrm{R} \$ 100$ milhões em 1995 e de R \$ 265 milhões em 1996 foram financiadas com o não-pagamento da energia adquirida da Eletronorte - a Cemat gerava apenas $8 \%$ da energia que distribuía.

Entre os fatores determinantes de sua crise, pode-se apontar a unificação tarifária antes de 1993, que não cobria os elevados custos operacionais da companhia em razão da dimensão territorial de Mato Grosso e de sua baixa densidade populacional, o que ocorre em toda a Amazônia Legal; perdas técnicas e gerenciais devido à pouca manutenção dos equipamentos e à sua sobrecarga, o que resultou em freqüentes blecautes, que chegaram a $27 \%$, o dobro do padrão setorial; e custos operacionais elevados em razão do excesso de funcionários, salários acima da média do mercado e o uso de energia em áreas remotas de baixa eficiência por meio de geradores movidos a diesel. A Cemat não conseguia, portanto, acompanhar o crescimento da economia estadual, impedia a sua continuidade por meio de desinvestimento em alguns setores e ameaçava a população com o espectro do desabastecimento energético.

Uma boa evidência desses argumentos é a participação que a energia hidráulica/eletricidade tinha na matriz energética estadual em 1995 e como foi sua evolução até 2001. Na produção de energia primária, destacavam-se o bagaço e o caldo da cana-de-acúcar e a lenha, o que se explicava pela elevada produção de cana-de-açúcar e extração de madeira no território estadual, com queda para a lenha e o crescimento para a energia hidráulica desde então.

Na produção de energia secundária, destacavam-se o carvão vegetal e o álcool etílico e hidratado, com a eletricidade respondendo por apenas 47,42\% da produção em 1995. Em 2001, o quadro havia-se alterado para $73,49 \%$, com forte queda do álcool etílico. É importante observar que a maior parte do consumo de energia no estado destina-se ao setor de transportes, com 40,73\%, em virtude da amplitude do território estadual e do volume físico das exportações e dos bens industriais importados de outros estados, e 21,01\% para o setor residencial em 1995, caindo para 
$16,17 \%$ em 2001, a despeito do crescimento do número de consumidores. $\mathrm{O}$ setor agropecuário e o industrial tinham pouca presença na matriz energética em 2000 (13,3\% e 28,3\%, respectivamente), com predominância de outras fontes mais caras.

O setor elétrico tem, como apontado anteriormente, elevada presença da União tanto no que se refere à concentração dos principais ativos de geração e transmissão, quanto pelo fato de a energia elétrica ser um serviço público federal cujas concessionárias são as distribuidoras estaduais ou as particulares. A exemplo do reordenamento das finanças públicas, que atribuía à União elevada capacidade de iniciativa pelo controle dos recursos tributários e instrumentais de política cambial e monetária no Banco Central, a reforma teria de começar pela União, e não apenas nos seus aspectos jurídicos.

Um dos fatores que dificultaram a alternativa de privatização acelerada do setor foram os elevados débitos que algumas distribuidoras estaduais tinham com as geradoras federais. A privatização, numa sequiência lógica, deveria começar pela geração, atividade em que os investimentos são mais volumosos e necessários. Porém, se a Eletrobrás fosse privatizada, os compradores levariam junto com seu ativo direitos a receber referentes à energia vendida e não paga pelas distribuidoras; essa negociação teria de ser feita num segundo momento, pois poderia gerar problemas de solvência e liquidez das companhias já privatizadas, comprometendo-se o seu desempenho com a ocorrência de privatização em cadeia, pela aquisição das ações das companhias pela Eletrobrás.

Isso fortaleceu a posição da primeira coalizão, que não desejava a privatização, e deu à segunda uma via pela qual poderia avançar em seus objetivos, ainda que de forma restrita e tecnicamente imprópria começando a privatização pela distribuição - seria como iniciar a reformulação da indústria automobilística pelas concessionárias de veículos. Como seus objetivos eram o reordenamento das finanças estaduais, com a eliminação de fontes do déficit público, e a renegociação da dívida pública, os aspectos técnicos setoriais não tiveram tanto peso.

A Cemat foi preparada, portanto, para a privatização. Essa decisão foi determinada por seus maus indicadores operacionais e financeiros, por sua concentração apenas na atividade de distribuição, que não exigia reestruturação muito complexa, pela frágil situação financeira, orçamentária e patrimonial do Estado de Mato Grosso no contexto da renegociação da dívida e pela postura da União no setor elétrico a partir de 1995.

Tal postura contemplou a ênfase nas Pequenas Centrais Hidrelétricas $(\mathrm{PCH})$, para reduzir os custos de transmissão, aproximando as fontes geradoras dos locais de consumo; a conclusão do acordo que se vinha arrastando desde a década de 1960 com a Bolívia para viabilizar o gasoduto, possibilitando, assim, a instalação de usina termelétrica em Cuiabá; e a 
retomada das obras da Usina de Manso por Furnas, com participação do capital privado, conforme a Lei no 9.074/95.

Esses dois empreendimentos fizeram a capacidade instalada de geração elétrica em Mato Grosso sair de 123,9 MW em 1993 para 559,73 MW, com potencial instalado de $856 \mathrm{MW}$, enquanto o consumo está na faixa de 600 MW. O estado ainda possui elevada dependência externa, medida pela relação produção/consumo de 52,4\% em 2001, embora essa relação tenha caído desde 1995. Contudo, esse consumo inclui os derivados do petróleo (gasolina, óleo diesel, querosene, lubrificantes) importados, que mantêm elevada presença na nossa matriz energética, em especial nos setores de transporte e agropecuário, que respondiam por $34,65 \%$ e $12,71 \%$ do consumo final em 2001, respectivamente.

Tais obras, que respondem por cerca de $90 \%$ da capacidade instalada, complementada por algumas PCHs, inclusive de propriedade da Rede Cemat, e aliadas a investimentos em transmissão, que ampliaram a extensão das linhas em 36,23\% de 1997 a 2002, equacionaram o problema energético do Estado de Mato Grosso, pelo menos a curto e médio prazos. A privatização da Cemat ocorreu nesse quadro e sozinha não teria alterado o quadro da primeira metade dos anos de 1990 por tratar-se, na essência, de uma distribuidora.

O Banco Nacional de Desenvolvimento Econômico e Social (BNDES), principal agente da privatização no Brasil desde a década de 1980 e cujo papel foi fortalecido pelo Programa Nacional de Desestatização, assumiu posição de destaque também em relação aos estados. O envolvimento foi possível pela Decisão no 316, de 15/8/1996, de sua diretoria, que disciplinou os procedimentos de antecipação de recursos lastreados nas receitas das futuras privatizações, a criação de fundo rotativo para esse fim e do Programa de Estímulo às Privatizações Estaduais (Pepe).

O primeiro estado beneficiado com esse procedimento foi Minas Gerais, em dezembro de 1995, comprometido, então, com a privatização da Cemig. Como tal alternativa foi trocada por mudança na composição acionária da companhia para incluir um sócio estrangeiro, o BNDES passou a exigir que os estados obtivessem aprovações de suas assembléias legislativas para a alienação das ações, o que foi feito em Mato Grosso pela Lei no ${ }^{-6.769}$, de 29/5/1996. No caso da Cemat, houve a subscrição de debêntures para uma subsidiária do BNDES, que se denomina Bndespar e administra participações em outras companhias, conversíveis em ações no momento da privatização, o que também foi feito para a Eletrobrás.

Em 10 de setembro de 1996, o governo estadual celebrou um contrato de gestão compartilhada com o BNDES e a Eletrobrás, forma de contrato que muitos consideraram como eufemismo de federalização. A nova equipe designada tinha como objetivo conduzir ações de: redução do 
quadro de pessoal, com demissão e aposentadorias, incluindo os funcionários de salários mais altos; redução de perdas operacionais; investimentos emergenciais para prevenir blecautes; renegociação dos débitos federais; e resolução de disputas legais.

Os principais resultados desse período foram os seguintes:

1) o número de funcionários de altos salários caiu de $2.636 \mathrm{em}$ dezembro de 1995 para 2.129 em um ano e para 1.538 em dois anos (41,6\%). O número de empregados de serviços terceirizados, predominantemente da área de manutenção de equipamentos, saiu de zero antes da privatização para 1.098 depois, constituídos, em grande parte, de ex-funcionários da Cemat, que abriram empresas ou cooperativas de serviço com os recursos recebidos por conta da demissão, o que é importante para compreender a formação da coalizão que viabilizou a privatização;

2) a folha de pagamento caiu de cerca de $R \$ 6$ milhões antes da privatização para $\mathrm{R} \$ 4,8$ milhões depois e o salário médio caiu de $\mathrm{R} \$$ $3.895,45$ para $\mathrm{R} \$ 1.819,40$. O custo/benefício anual estimado com essa redução está na faixa de $\mathrm{R} \$ 15,6$ milhões;

3) o número de consumidores cresceu $6 \%$ e a relação consumidor/ funcionário cresceu de 220 em 1996 para 324 em 1997 e para 365 em 2001;

4) os investimentos de emergência foram implementados com a capitalização do BNDES e da Eletrobrás, que receberam debêntures conversíveis em ações como caução;

5 ) as perdas totais foram reduzidas de 26,8\% em 1996 para 25,1\% em 1997, nível considerado alto ainda, resultado de problemas, em sua maioria, com medidores defasados;

6) os débitos federais com o FGTS, INSS e Receita Federal foram renegociados e as compras de energia da Eletronorte/Eletrobrás foram capitalizadas.

Pode-se resumir a privatização da Cemat nos seguintes passos:

1) um consórcio de empresas brasileiras liderado pela Maxima foi contratado, nos moldes de outras privatizações realizadas pelo BNDES, para preparar a privatização. A consultoria começou em janeiro de 1997 e, a despeito de alguns atrasos iniciais, a privatização ocorreu na Bolsa de Valores do Rio de Janeiro, em 27/11/1997;

2) fez-se a opção por venda em bloco único sem desmembramento das atividades de geração e distribuição, nos termos do modelo proposto pela Coopers \& Lybrand, embora os contratos de concessão apontassem a necessidade de criação de duas companhias independentes em três anos. Os modelos de privatização, em geral, respondem às coalizões que os formuladores pretendem montar para viabilizar a política. No Brasil, por conta da forte associação entre as privatizações e a política fiscal, optou-se pelos leilões, que poderiam maximizar o valor das companhias 
vendidas, em vez de vendas a preço fixo com base na pulverização de ações ao público, opção controversa para alguns, pois induz a um aumento tarifário depois, para que o recurso empregado na privatização seja recuperado. No âmbito do PND, entre 1990 e 1995, as privatizações seguiram o que Velasco JR (1997) chama de "Modelo Usiminas" - indústria do ramo siderúrgico selecionada para ser o leading case e conferir credibilidade ao PND -, em que o agente não definia quantidades mínimas a serem adquiridas nem pré-qualificações dos candidatos. Tratava apenas de zelar pelas regras do jogo, abrindo a possibilidade de diversos cenários de vencedores e ampliando, portanto, a coalizão de defensores, em especial com o empresariado. A partir de 1995, com a ampliação do consenso em razão do Plano Real, entre outros fatores, foi possível adotar um modelo que preconizava determinada composição acionária para a companhia, após a privatização, e reduzia o número de possíveis vencedores. A Cemat e demais companhias do setor elétrico seguiram esse padrão, portanto;

3) cerca de $12 \%$ das ações ordinárias (capital votante) foram oferecidos aos funcionários da Cemat com deságio de $50 \%$ em relação ao preço mínimo definido para a privatização ( $\mathrm{R}$ \$ 323,3 milhões). A experiência internacional recomendava atenção especial aos funcionários, em virtude da elevada capacidade demonstrada de obstrução das privatizações, seja pela via da sabotagem (resistência tácita) ou mesmo da aliança com outros segmentos sociais e políticos opositores por razões políticas e programáticas, como o Judiciário, o Legislativo, o Ministério Público, a imprensa, ONGs, o empresariado, partidos ou parlamentares. No caso da Cemat, além do plano de aposentadoria e demissão implementado antes da privatização, houve a separação de um lote de ações ordinárias a ser oferecido aos funcionários, cuja liquidação foi prorrogada várias vezes, exigiu muita atenção do CDPRE no primeiro semestre de 1998 e envolveu a utilização de créditos trabalhistas e a participação do fundo de pensão - o Previmat. Em maio de 1999, o CDPRE diligencia junto à Eletrobrás a venda de suas ações remanescentes;

4) o BNDES ofereceu financiamento para os interessados na compra;

5) as companhias tiveram de se pré-qualificar e depositar garantias referentes ao preço mínimo antes do leilão na Bolsa de Valores;

6) o leilão ocorreu em 27/11/96 na Bolsa de Valores do Rio de Janeiro. Outras seis companhias estaduais foram leiloadas apenas nos meses de outubro e novembro de 1997 (CEEE Centro-Oeste, CEEE NorteNordeste, CPFL, Enersul, Energipe e Cosern);

7) de cinco companhias pré-qualificadas, três participaram do leilão e duas destas formaram um consórcio. Na primeira rodada, as propostas foram feitas em envelope fechado e ganhou o consórcio CataguazesLeolpoldina e a Light, que apresentou proposta de $14,4 \%$ acima do preço 
mínimo. De acordo com a legislação e de forma inédita até então, foi necessária uma segunda rodada, em viva voz, pela diferença inferior a $10 \%$ da proposta do consórcio Rede/Inepar, que deu o lance de $\mathrm{R}$ \$ 391,5 milhões, vencendo o leilão. Não houve participação de companhias estrangeiras no leilão, pois estas privilegiaram distribuidoras maiores, localizadas nas regiões Sul, Sudeste e Nordeste. É importante lembrar que a Cemat obteve um dos menores ágios $(21,09 \%)$ e valores pagos por MWH (na faixa de 180 a 190);

8) os R $\$ 391,5$ milhões pagos pela Rede/Inepar foram assim distribuídos: R \$ 176,1 milhões para o Estado de Mato Grosso, R \$ 139,98 milhões para a Eletrobrás, R\$ 18,33 milhões para o BNDES, R \$ 16,28 milhões para a BNDESPAR, $\mathrm{R} \$ 40,6$ milhões para a própria Cemat e $\mathrm{R} \$ 195.750$ para os custos da privatização;

9) os $\mathrm{R} \$ 176,1$ milhões do estado foram distribuídos da seguinte forma: $\mathrm{R}$ \$ 66 milhões para pagamento de dívidas contratuais com a União e o BID, R \$ 11,4 milhões para dívidas de ICMS de energia elétrica com os municípios, R\$ 53 milhões para 13o salário dos três poderes em 1997 , R\$ 14 milhões para investimentos em projetos sociais e rodoviários, $\mathrm{R}$ \$ 25,9 milhões para a complementação das folhas de pagamento de janeiro, fevereiro e março de 1998 e R \$ 5,8 milhões para pagamento do 13ํㅗㄴ salário dos servidores municipais de Cuiabá. Tal composição é importante para compreender a coalizão de apoio à privatização. Boa parte das operações realizadas com recursos egressos da privatização seria proibida hoje pela Lei de Responsabilidade Fiscal, que, pela sua "regra de ouro", vincula as receitas de capital apenas às despesas de capital.

O Grupo Rede, com origem no Estado de São Paulo, é composto de sete concessionárias controladas por uma holding, denominada Empresa de Energia do Vale do Paranapanema (EEVP), que, por sua vez, é controlada pela Denerge S.A. A empresa Cauia é a titular das ações da Cemat pertencentes ao grupo. A sua atuação consiste na geração, transmissão e distribuição de energia para cerca de $30 \%$ do território nacional, isto é, mais de 2,5 milhões de consumidores, com benefício direto a mais de 11 milhões de pessoas.

Além da Cemat, o grupo tem a concessão de companhias nos Estados de São Paulo (71 municípios), Minas Gerais (10 municípios), Paraná (1 município), Pará (Celpa) e Tocantins (Celtins). Neste último, o grupo participa da construção de uma usina hidrelétrica no Rio Tocantins com capacidade estimada em 850 MW. A Inepar é um grupo do Estado do Paraná, que possui investimentos em geração, equipamentos elétricos, automação de sistemas, medidores de energia, telemetria e telecomunicações. Está em fase de constituição uma companhia apenas de geração (Rede Power), conforme a Lei n⿳ำ 9.648/98 e as exigências da Aneel. 
Apesar dos esforços feitos durante a vigência do contrato de gestão compartilhada, algumas dívidas ainda foram transferidas para os compradores da Cemat por ocasião da privatização (US\$ 461 milhões). Segundo Bini (2002), a recuperação dos débitos federais, o pagamento de dívidas trabalhistas e os juros continuaram após a privatização e o passivo total evoluiu para R\$ 670,373 milhões em 2002. O faturamento bruto, entretanto, cresceu de R \$ 411,598 milhões em 1998 para R 715,702 milhões em 2001 - aumento de 73,88\%. Desconsiderando o serviço da dívida, a companhia é lucrativa.

Os indicadores operacionais e financeiros da companhia melhoraram após a privatização. De um prejuízo de $\mathrm{R}$ \$ 30,2 milhões em 1997, a Cemat obteve: lucro de R \$ 8,9 milhões em 1998, prejuízo de 2,4 milhões em 1999, prejuízo de $\mathrm{R} \$ 115,825$ milhões em 2000, lucro de $\mathrm{R} \$ 5,8$ milhões em 2001 e prejuízo de 111,685 milhões em 2002. Essa gangorra derivou da parcela elevada do passivo da companhia, dolarizado (cerca de $40 \%$ no final de 1999), que aumentou o montante e seu serviço, em especial nos anos de forte desvalorização cambial, como 1999 e 2002, em que o dólar chegou a ser comercializado a $\mathrm{R} \$ 4,00$, logo após o 1ำ turno das eleições de outubro. A companhia deve seguir, portanto, os passos de outras distribuidoras privatizadas e dolarizar também parcela de seus ativos para compensar eventuais desvalorizações, numa operação que o mercado financeiro chama de hedge ou cobertura cambial.

\section{Considerações finais}

Nesta seção, serão apresentados os resultados da pesquisa e suas conclusões. Para tanto, retornar-se-á ao seu referencial metodológico para verificar a sua validade. O problema foi enunciado da seguinte forma: quais foram as variáveis críticas para a formação da coalizão social e política que viabilizou a privatização da Cemat, na perspectiva da governabilidade democrática?

Para responder a essa pergunta, foram apresentadas quatro hipóteses, baseadas na compreensão teórico-conceitual da governabilidade e governança. Far-se-á, agora, uma revisão de cada uma delas para que sejam verificadas as evidências reunidas pela pesquisa e seja possível demonstrar a sua validade de acordo com o problema.

Hipótese 1 - A situação do setor elétrico no Brasil e alguns indicadores relativos à Cemat (estrutura desverticalizada, funcionários, indicadores financeiros e operacionais, passivo, localização, dimensão) contribuíram para a privatização.

Pode-se observar que o fato de a Cemat ser uma companhia com ativos concentrados na distribuição, com maus indicadores operacionais e 
financeiros e um passivo elevado, sobretudo por conta de energia não paga adquirida da Eletrobrás, facilitou a sua privatização. O modelo proposto pela Coopers \& Lybrand, em 1996, e depois incorporado pela Lei no 9.648/ 98 tinha como um dos fundamentos a separação das funções de geração, transmissão e distribuição em companhias diferentes para a formação de ambiente competitivo.

No caso das companhias que reuniam essas três áreas, aquelas situadas nos estados mais industrializados, pelas razões apontadas, era necessária a reestruturação nos marcos legais para a atuação na nova estrutura preconizada pelo mercado. As companhias que fizeram tal separação, como a Cesp e a CEEE, limitaram a privatização aos seus ativos de distribuição, impondo limites à geração e transmissão. Como a Cemat é uma distribuidora, sua reestruturação foi mais rápida e simples, o que facilitou a privatização.

Viu-se que a solução do problema de abastecimento energético em Mato Grosso passou pela nova postura da União no setor, a partir de 1995, e por decisões importantes da Eletrobrás e das suas subsidiárias Furnas e Eletronorte. A conclusão do acordo Brasil-Bolívia, que viabilizou o gasoduto e a usina termelétrica de Cuiabá, com capacidade de 480 MW, e a retomada das obras da Usina de Manso, com participação do capital privado nos termos da Lei no $\mathbf{9}$ 974/95, elevaram a capacidade de geração instalada no território estadual para cerca de $560 \mathrm{MW}$, com potencial de $856 \mathrm{MW}$ e consumo na faixa de $600 \mathrm{MW}$.

Já que o potencial hidrelétrico nas regiões Sul e Sudeste do Brasil está próximo do esgotamento e a expansão do consumo nessas regiões deve ser suprida por outros modais energéticos (nuclear, termelétrica, eólica, solar) e/ou pela importação de outros estados ou países, a fronteira desse potencial desloca-se para as regiões Norte e Centro-Oeste, onde se concentram os maiores investimentos atuais.

A Eletrobrás, em sua estratégia de fortalecimento para evitar a privatização, não tomaria tais decisões sem que houvesse a garantia de uma distribuidora em Mato Grosso com bons indicadores operacionais e financeiros e, sobretudo, que pagasse pela energia comprada. O grupo Rede adquiriu cerca de $65 \%$ do capital total da Cemat na ocasião da sua privatização, em 1997. Em virtude do passivo transferido, avaliado, então, em US\$ 461 milhões, sobre o qual pesavam os débitos com a Eletrobrás, a companhia, em 2/4/1998, aumentou o capital e ofereceu à Eletrobrás um lote de ações preferenciais, quitando uma dívida de $\mathrm{R} \$ 285$ milhões, além dos cerca de $\mathrm{R} \$ 140$ milhões pagos na privatização.

Essa operação, do ponto de vista técnico, reestatizou a companhia, pois, segundo a sua composição acionária em maio de 2000 (veja Anexo II), a Eletrobrás é a acionista majoritária tanto no total de ações quanto 
nas preferenciais $(59,8 \%)$, enquanto o grupo Rede detém 56,98\% das ordinárias, que lhe conferem a direção da companhia.

A Eletrobrás buscou parceiros na região para contribuir com a reestruturação da companhia e, no aporte financeiro, deve ter condicionado os investimentos realizados em Mato Grosso à privatização e visualizou a posterior reestatização por meio do passivo elevado, num mercado com baixas condições de crédito e liquidez. Essa era uma das razões apontadas para não se iniciar a privatização pelas geradoras, pois seria desencadeada reação em cadeia e reconcentração por conta do passivo das distribuidoras estaduais, o que geraria um monopólio privado no lugar do estatal.

A privatização, portanto, das distribuidoras estaduais, como a Cemat, fez parte do saneamento financeiro e da ampliação de sobrevida da Eletrobrás como estatal, por sua capacidade de contribuição para a política fiscal - leia-se superávit primário - com parte de seus lucros. A aquisição pela empresa italiana Enel de $30 \%$ do capital da Inepar Energia (detentora de 18,11\% da Cemat), em 25/7/2000, internacionalizou-a de forma indireta. Essa composição faz da Cemat uma espécie de "fratura exposta" da falta de consenso entre as elites sobre o setor elétrico, pois conta com participação do capital estatal, privado e internacional.

A confluência de várias coalizões com objetivos estratégicos diferentes em torno da privatização da Cemat, sem orientação comum para o setor elétrico, gerou esse modelo anfíbio, nos termos de Landau (2001), com cerca de $60 \%$ dos ativos de geração concentrados em uma companhia estatal oligopolista - a Eletrobrás -, para a qual não valem as metas compulsórias de abertura de capital, a presença na Bolsa de Valores e o marco regulatório aplicado às distribuidoras "privadas" pela Aneel.

A prova mais clara disso é a não-adesão da Eletrobrás e de suas subsidiárias aos parâmetros do modelo proposto pela Coopers \& Lybrand, no que se refere ao Mercado Atacadista de Energia (MAE), que está paralisado e com os preços baixos pela alta oferta, o que fundamenta a recusa de as principais geradoras do país participarem nesse processo de privatização. Pode-se afirmar, portanto, que a hipótese formulada revelou-se plausível, necessitando de "aproximações sucessivas" por meio de estudos comparativos, para se observar se as variáveis comportaram-se da forma a ampliar a sua capacidade de generalização para outros casos.

\section{Hipótese 2 - A situação orçamentária, financeira e patrimonial do Estado de Mato Grosso estava deteriorada}

Os indicadores financeiros e patrimoniais estavam numa situação frágil em 1994, os quais posicionavam o Estado de Mato Grosso entre os piores nos rankings do setor. 
Essa condição deu pouca margem ao governo estadual na renegociação da dívida com a União, e Mato Grosso não tinha outros ativos a oferecer para quitar os $20 \%$ do principal à vista, nos termos do acordo com outros estados. Goiás não vendeu a sua companhia de eletricidade (Celg) naquele período, mas privatizou a Usina de Cachoeira Dourada, federalizou o seu banco (BEG) e liquidou a sua Caixa Econômica (Caixego). Minas Gerais não privatizou a Cemig, embora tenha mudado a sua composição acionária e reestruturado a empresa nos termos da Lei no 9.648/98, mas privatizou seus bancos Bemge e Credireal. Mato Grosso do Sul, por ser estado novo, não possuía banco estadual, não tinha condição financeirapatrimonial como a de Mato Grosso e teve de privatizar a Enersul.

A situação financeira deteriorada do estado ajuda a explicar também a privatização da Cemat, pela utilização dada por Mato Grosso à sua receita: pagamento de despesas "antigas", como parte do ajuste fiscal (48\% para salários atrasados e $44 \%$ para quitação de dívidas anteriores). Lembre-se também de que, entre os três ganhos de uma privatização para a política fiscal - pagamento da dívida, redução do déficit e arrecadação de impostos -, a Cemat enquadrou-se nos três.

Após a privatização, a companhia passou a recolher com regularidade o ICMS sobre a energia, que foi escalonado segundo as faixas de consumo. Houve contribuição, portanto, também pelo lado da receita com a arrecadação de ICMS, ou seja, a privatização foi parte importante do ajuste fiscal promovido pelo Estado de Mato Grosso, situação esta que, se fosse melhor, não era necessária.

Enfim, pode-se considerar essa hipótese plausível pela forte contribuição das variáveis financeiras, orçamentárias e patrimoniais para a privatização.

\section{Hipótese 3 - A formação de uma coalizão nacional voltada para a reforma do Estado e de seu aparelho, adotada a partir de 1995, contribuiu para o avanço desse processo em nível estadual}

Dentre os fatores que contribuíram para a reversão do ultrapresidencialismo estadual, pode-se destacar a função exercida pelo Plano Real e por sua equipe de condutores. Este cumpriu papel reorganizador e legitimador da agenda nacional, tornando-se fator condicionante das demais reformas, vistas desde então como determinantes para sua manutenção.

A articulação iniciada no Parlamento, depois submetida ao voto popular e aprovada, colocou as reformas estruturais no centro da gravidade ideológica nacional. As elites e a opinião pública em geral, que já vinham passando por movimento lento de conversão sobre a necessidade de reformar o Estado e ampliar a participação do mercado na economia, em virtude das crises da década de 1980 - que causaram desgaste à matriz estadocêntrica, responsável pela industrialização no Brasil -, 
aceitaram o imperativo das reformas voltadas para o mercado. Segundo

Melo (2002), o movimento mais amplo de desideologização do debate sobre as reformas socioeconômicas produziu consenso pragmático e gerou alinhamento programático entre o governo e o empresariado.

Na eleição de 1994, um conjunto de forças políticas condicionou, em grande medida, a sua sobrevivência na arena nacional ao resultado do Plano Real e promoveu divisão de tarefas entre os Poderes Legislativo e Executivo. As tarefas necessárias para a condução do plano eram consideradas inegociáveis e seriam realizadas pelo próprio presidente e pela sua "ala tecnocrática", montada desde sua passagem prévia pelos Ministérios das Relações Exteriores e da Fazenda. Uma citação de Diniz (2000, p. 91) exemplifica bem esse fenômeno.

"O êxito do plano no sentido de reduzir drasticamente a inflação e quebrar os mecanismos de indexação da economia representou um importante capital político para o Ministro da Fazenda e depois Presidente Fernando Henrique Cardoso, ao longo dos quatro anos de seu primeiro mandato. Além disso, foi um fator de governabilidade, garantindo um consenso básico em torno da política de estabilização econômica e favorecendo a unidade da complexa e heterogênea coalizão governamental."

Essa coalizão, que envolveu agências centrais, como o Banco Central, o BNDES e os Ministérios da Fazenda e do Planejamento, teve como objetivo, portanto, consolidar o plano de estabilização, por meio de políticas macroeconômicas consideradas necessárias, com elevada autonomia em relação às principais clientelas, o que as torna entidades politicamente posicionadas, conforme a literatura específica. Em relação ao Estado de Mato Grosso, tal coalizão contribuiu para o acordo de renegociação da dívida, a privatização da Cemat, a aprovação do Programa de Reforma do Estado, garantido pela União, e também do Pnafe.

Por isso, considera-se que essa hipótese também se revelou plausível pelas evidências apresentadas pela pesquisa, devendo ser mais aprofundada para ampliar sua capacidade de generalização.

\section{Hipótese 4 - A dinâmica político-institucional dos estados brasileiros e o seu posicionamento no contexto federativo influenciaram o processo decisório relativo às políticas de reforma e o ajustamento estrutural em Mato Grosso}

Os mecanismos do ultrapresidencialismo estadual descritos por Abrúcio (1998) foram utilizados pelo Governador Dante de Oliveira para a realização da reforma do estado e de seu aparelho em Mato Grosso. Pode-se elencar aqui a aprovação de todo o marco jurídico relativo à reforma pela Assembléia Legislativa, a aprovação da privatização da 

das iniciativas nesta área pelo Poder Judiciário, pelo Ministério Público Estadual e pela imprensa.

Contudo, os padrões de comportamento parlamentar, denominados por Abrúcio de "governismo" e "situacionismo", também se fizeram presentes no acordo de renegociação das dívidas e no Programa de Reforma do Estado. O empréstimo, após aprovação pelo Bird, em junho de 1997, ficou cerca de um ano e meio em discussão no Senado e também na Assembléia Legislativa.

Os parlamentares fizeram alterações nas categorias de investimento e garantiram a manutenção de algumas entidades da administração indireta, como a Sanemat e a Empaer, ou seja, mesmo fazendo oposição ao governador, eles, articulados com outros atores, quiseram conformar o conteúdo do programa, reproduzindo o padrão de independência (posicionaram-se como situação nas obras, no seu distrito informal, e como oposição nas políticas estaduais, de forma geral).

Essa hipótese também se revelou plausível, embora com relativa escassez de dados empíricos em razão das limitações operacionais da pesquisa. A exemplo das outras hipóteses, esta precisa de "aproximações sucessivas" para que se verifiquem sua validade e sua capacidade de generalização.

Pode-se afirmar que a interação das variáveis críticas apontadas nas hipóteses viabilizou a formação do consenso social e político necessário para a privatização da Cemat. A pesquisa demonstrou, portanto, que as comparações do setor elétrico com as do setor de telecomunicações não são ilustrativas das dificuldades enfrentadas pelo primeiro durante a desestatização.

Talvez haja maior similaridade do setor elétrico com o de transportes, que também vem atravessando dificuldades desde os anos de 1980, pelo esgotamento da matriz rodoviária, pela afirmação de outros modais, por ter ativos distribuídos pelos três níveis da Federação e ainda não ter conseguido avançar na desestatização, pela existência de coalizão muito forte de apoio ao atual modelo, que articula atores nacionais e internacionais. A falta de consenso nessa área e as dificuldades técnicas imanentes barraram projetos mudancistas de maior envergadura, e elevados investimentos são destinados a "enxugar gelo", a exemplo do que ocorre no setor elétrico.

Por fim, ressaltem-se a capacidade de análise da reforma do Estado e de seu aparelho das categorias governabilidade e governança, conforme a orientação proposta nesta pesquisa, e a sua utilidade para aplicação em outros objetos.

Com esta pesquisa, não se pretende esgotar o tema, mas esperase que ela tenha cumprido os seus objetivos. Existirá um túnel no fim da luz para o setor elétrico? 


\section{Referências bibliográficas}

ABrúcio, Fernando Luiz. O ultrapresidencialismo estadual. In: AndRADE, Régis de Castro (Org.). Processo de governo no município e no Estado. São Paulo: EDUSP, 1998.

Os barões da federação. São Paulo: Hucitec, 1996.

Reforma do Estado e federalismo: o caso dos governos estaduais brasileiros. Versão modificada do paper apresentado em seminário organizado pela Fundação Joaquim Nabuco entitulado "O longo caminho das reformas nos governos estaduais brasileiros: crise mudanças e impasses". São Paulo, 2000. Mimeografado.

Albano, Valter. Do caos ao equilíbrio fiscal: uma difícil travessia. Cuiabá: Entrelinhas, 2001.

ARAúso, Vinícius de Carvalho. A conceituação da governabilidade e governança, da sua relação entre si e com o conjunto reforma do Estado e de seu aparelho. Brasília: ENAP, 2002. (Texto para Discussão no 45.) Disponível em: 〈http://www.enap.gov.br〉. Acesso em: 9 maio 2002.

A conceituação da governabilidade e governança, da sua relação entre si e com o conjunto reforma do Estado e de seu aparelho. Revista Desarollo Humano y Institucional em América Latina - DHIAL no 41. Barcelona: Instituto Internacional de Gobernabilidad, 2003.

Borges, Fernando Tadeu de Miranda. Do extrativismo à pecuária: algumas observações sobre a história econômica de Mato Grosso (1870-1930). São Paulo: Scortecci, 2001.

BRASIL. Ministério do Planejamento, Orçamento e Gestão. Balanço da reforma do Estado no Brasil: a nova gestão pública. Brasília: 2002. (Coleção Gestão Pública.)

Bresser Pereira, Luiz Carlos; Wilheim, Jorge; Sola, Lourdes (Org.). Sociedade e Estado em transformação. São Paulo: UNESP; Brasília: ENAP, 2001.

CATALÁ, Joan Prats I. Administración pública y desarollo em América Latina: um enfoque neoinstitucionalista. Revista Del CLAD Reforma Y Democracia n. 11. Caracas: CLAD, Junio de 1998a.

DRAIBE, Sônia. Rumos e metamorfoses: Estado e industrialização no Brasil 1930/1960. São Paulo: Paz e Terra, 1985.

Ferreira, Carlos Kawall Leal. A privatização do setor elétrico. In: Pinheiro, Armando Castelar; FuKasaku, Kiichiro. A privatização no Brasil: o caso dos serviços de utilidade pública. Rio de Janeiro: BNDES, 1999.

FretTAS, Jomini Falcão. A ouvidoria da Agência Estadual de Regulação dos Serviços Públicos Estaduais Delegados em Mato Grosso-AGER/MT: um estudo de caso na área de energia elétrica. Monografia apresentada para obtenção do título de especialista em Gestão Pública e Finanças na FAECC/UFMT. Cuiabá, 2003. Mimeografado.

Giambiagi, Fábio; AlÉm, Ana Cláudia. Ajuste do governo central: além das reformas. In: Giambiagi, Fábio; Moreira, Maurício Mesquita. A economia brasileira nos anos 90. Rio de Janeiro: BNDES, 1999.

Giambiagi, Fábio; Moreira, Maurício Mesquita. A economia brasileira nos anos 90. Rio de Janeiro: BNDES, 1999.

Giambiagi, Fábio; Rigolon, Francisco. Renegociação das dívidas e regime fiscal dos Estados. Rio de Janeiro: BNDES, 1999. (Texto para discussão 69). 
Giambiagi, Fábio. Do déficit de metas à meta de déficits: a política fiscal do governo Fernando Henrique Cardoso - 1995/2002. Rio de Janeiro: BNDES, 2002. (Texto para discussão 93)

Necessidades de financiamento do setor público: bases para discussão do ajuste fiscal no Brasil: 1991-1996. Texto para discussão 53. Rio de Janeiro: BNDES, 1997.

Giambiagi, Fábio; Pinheiro, Armando Castelar; Gostkorzewicz, Joana. O desempenho macroeconômico do Brasil nos anos 90. In: Giambiagi, Fábio; Moreira, Maurício Mesquita. A economia brasileira nos anos 90. Rio de Janeiro: BNDES, 1999.

Giambiagi, Fábio; Pires, José Cláudio Linhares; Sales, André Franco. As perspectivas do setor elétrico após o racionamento. Revista do BNDES. Rio de Janeiro, v. 9, no 18, p.163204, 2002.

GIL, Antonio Carlos. Como elaborar projetos de pesquisa. São Paulo: Atlas, 1994.

Gomide, Francisco Luiz. O futuro do modelo energético no Brasil. Apresentação feita no seminário do jornal Valor Econômico em 30/8/2002. Mimeografado.

LANDAu, Elena. Privatização: a verdadeira e a falsa. O Estado de S. Paulo, São Paulo, 9/9/ 2001 .

LEAL, Cláudio Figueiredo Coelho. Ágios, envelopes e surpresas: uma visão geral da privatização das distribuidoras estaduais de energia elétrica. Rio de Janeiro: BNDES. Mimeografado.

LoRA, Eduardo. What makes reforms likely? Timing and sequencing of structural reforms in Latin America. BID, 2000. (Working Paper 424).

. Reforma da administração pública e cultura política no Brasil: uma visão geral. Brasília: ENAP, 1995. (Cadernos ENAP, 8)

Mato Grosso. Secretaria de Estado de Planejamento e Coordenação Geral. Balanço energético de Mato Grosso e mesorregiões (1995-2001). Cuiabá, 2002.

PARENTE, Pedro. Perspectivas da energia no Brasil: desafios e expectativas. Brasília: Câmara de Gestão da Crise de Energia, 2001.

Pinheiro, Armando Castelar; Fukasaku, Kiichiro. A privatização no Brasil: o caso dos serviços de utilidade pública. Rio de Janeiro: BNDES, 1999.

PinheIro, Armando Castelar; GiAmBiAgi, Fábio. Os antecedentes macroeconômicos e a estrutura institucional no Brasil. In: PInHEIRo, Armando Castelar; FuKASAKU, Kiichiro. A privatização no Brasil: o caso dos serviços de utilidade pública. Rio de Janeiro: BNDES, 1999.

PINHEIRO, Armando Castelar. A experiência brasileira de privatização: o que vem a seguir?. Rio de Janeiro: BNDES, 2000. (Texto para Discussão, 87)

Privatização no Brasil. Por quê? Até onde? Até quando? In: Giambiagi, Fábio; MoreIra, Maurício Mesquita. A economia brasileira nos anos 90. Rio de Janeiro: BNDES, 1999.

PIREs, José Cláudio Linhares; PICCININI, Maurício Serrão. A regulação dos setores de infraestrutura no Brasil. In: Giambiagi, Fábio; Moreira, Maurício Mesquita. A economia brasileira nos anos 90. Rio de Janeiro: BNDES, 1999.

PIREs, José Cláudio Linhares. Desafios da reestruturação do setor elétrico. Rio de Janeiro: BNDES, 2000. (Texto para Discussão, 76)

Rhodes, R. A. W. Understanding governance. Buckingham: Open University Press, 1997.

SAntos, Gilton Carneiro dos. A dívida dos Estados: composição, evolução e concentração. Menção honrosa no tópico dívida pública no III prêmio de monografias do Tesouro Nacional 
SiqueIra, Ethevaldo. Telecomunicações. In: Lamounier, Bolívar; FigueIREDo, Rubens (Org.). A era FHC: um balanço. São Paulo: Cultura Editores Associados, 2002.

Sola, Lourdes (Org.). Estado, mercado e democracia. São Paulo: Paz e Terra, 1993.

VARGAS, Lília (Org.). Guia para apresentação de trabalhos científicos. Porto Alegre, 2001. Disponível em: 〈http://www. read.adm.ufrgs.br〉. Acesso em: 14 nov. 2002.

Velasco JR., Licínio. A economia política das políticas públicas: as privatizações e a reforma do Estado. Rio de Janeiro: BNDES, 1997. (Texto para Discussão, 54)

A economia política das políticas públicas e a reforma do Estado. Rio de Janeiro: BNDES, 1997. (Texto para Discussão, 55)

Privatização: mitos e falsas percepções. In: Giambiagi, Fábio; MoreIRA, Maurício Mesquita. A economia brasileira nos anos 90. Rio de Janeiro: BNDES, 1999. 


\section{Anexo I: Acertos realizados com recursos da venda das ações - leilão público (em milhões de reais)}

\begin{tabular}{l|c|c|c|c|c}
\hline Especificação & $\begin{array}{l}\text { Governo } \\
\text { de Mato } \\
\text { Grosso }\end{array}$ & Eletrobrás & BNDESPAR & BNDES & CEMAT \\
\hline $\begin{array}{l}\text { Valor líquido das } \\
\text { vendas das ações }\end{array}$ & 107.083 & 267.941 & 16.280 & - & - \\
\hline $\begin{array}{l}\text { (*) Pagamento } \\
\text { de obrigações } \\
\text { no BNDES }\end{array}$ & -18.334 & - & - & 18.334 & - \\
\hline $\begin{array}{l}\text { (**) Repasse da } \\
\text { Eletrobrás ao } \\
\text { Estado de MT }\end{array}$ & 87.361 & -87.361 & - & - & - \\
\hline $\begin{array}{l}\text { (**) Valor pago } \\
\text { à Cemat }\end{array}$ & - & -40.599 & - & - & 40.599 \\
\hline Total recebido & 176.110 & 139.982 & 16.280 & 18.334 & 40.599 \\
\hline
\end{tabular}

Observações:

1) Debêntures (Venda)

Eletrobrás

1.465 .117 .368

9.277.869.240
BNDESPAR

309.881 .000

1.962 .330 .000

Convertidas em ações preferenciais

$\mathrm{O}$ valor de $\mathrm{R} \$ 40.598 .756,06$ foi repassado diretamente à Cemat para quitar débitos do Estado de Mato Grosso, referentes ao Termo de Confissão de Dívida relativo aos créditos da Cemat com as prefeituras municipais, assumidos pelo Governo de Mato Grosso em 26/8/97 e ao saldo devedor dos recursos repassados ao Estado de Mato Grosso a título de antecipação a acionista, na operação de venda de 2.076 debêntures, efetuada em $5 / 8 / 96$

Fonte: Grupo de trabalho da reforma administrativa. Relatório analítico sobre as reformas 1995-2000. Cuiabá, 2000. 
Anexo II: Composição acionária da Rede/Cemat (Maio de 2000)

\begin{tabular}{l|c|c|c}
\hline Acionista & $\begin{array}{l}\% \text { das ações } \\
\text { ordinárias }\end{array}$ & $\begin{array}{c}\% \text { das ações } \\
\text { preferenciais }\end{array}$ & $\begin{array}{c}\% \text { do } \\
\text { capital } \\
\text { total }\end{array}$ \\
\hline $\begin{array}{l}\text { Grupo Rede/EEVP } \\
\text { (através da Caiuá) }\end{array}$ & 56,98 & 27,02 & 37,36 \\
\hline Inepar S.A. & 29,64 & 12,04 & 18,11 \\
\hline Eletrobrás e Furnas & 5,79 & 59,80 & 41,17 \\
\hline $\begin{array}{l}\text { Governo do Estado de } \\
\text { Mato Grosso (empregados) }\end{array}$ & 4,17 & - & 1,44 \\
\hline CODEMAT & 0,25 & - & 0,08 \\
\hline Outros & 3,17 & 1,14 & 1,84 \\
\hline Total & 100 & 100 & 100 \\
\hline
\end{tabular}

Fonte: International Bank for Reconstruction and Development (IBRD).

Implementation Completion Report for a Mato Grosso Privatization Project.

Washington, 2002. 
Revista do

Serviço

Público

Ano 55

Número 3

Jul-Set 2004

Vinícius de

Carvalho

Araújo é gestor governamental da Secretaria de Planejamento e

Coordenação

Geral (Seplan)

do Estado de

Mato Grosso e especialista em

Políticas e

Estratégias para

o Setor Público

pela

Universidade

Federal do

Mato Grosso.

Contato:

vcaraujo@

$\underline{\text { terra.com.br }}$

\section{Abstract}

\section{O túnel no fim da luz: a privatização do setor elétrico em Mato Grosso \\ Vinícius de Carvalho Araújo}

Este artigo tem por objetivo analisar a formação de consensos sociais e políticos para a reforma do Estado e de seu aparelho em nível estadual, conforme a governabilidade democrática. Optou-se por uma pesquisa sobre a privatização das Centrais Elétricas MatoGrossenses S.A. (Cemat), considerada representativa tanto da reforma empreendida pelo Estado de Mato Grosso quanto das dificuldades do setor elétrico em nível nacional. O referencial metodológico dessa pesquisa é composto de um problema e de quatro hipóteses de trabalho. Trata-se de estudo de caso da espécie "provas de plausibilidade", em que, por uma aplicação iterativa, apresenta-se uma proposição teórica inicial e, em seguida, as conclusões da pesquisa são comparadas, o que permite sua revisão e comparação. Para tanto, descrevem-se a privatização da Cemat e os problemas da desestatização do setor elétrico brasileiro no seu conjunto. Por fim, na conclusão, verifica-se a validade das hipóteses e fazem-se algumas considerações finais sobre a pesquisa.

\section{El túnel al final de la luz: la privatización del sector eléctrico en Mato Grosso \\ Vinícius de Carvalho Araújo}

Este artículo tiene como objetivo analizar la formación de consensos políticos y sociales para la reforma del Estado y su aparato en nivel estadual, en el marco de la gobernabilidad democrática. Seleccionamos una pesquisa sobre la privatización de la compañía Centrais Elétricas Mato-Grossenses S.A. (Cemat), considerada representativa tanto de la reforma realizada por el Estado de Mato Grosso cuanto de las dificultades del sector eléctrico en nivel nacional. Su referencial metodológico consiste en un problema más cuatro hipótesis de trabajo. Trata-se de un estudio de caso de la especie "pruebas de plausibilidad" que, atraves de una aplicación iterativa una proposición teórica inicial es hecha y las conclusiones de la pesquisa comparadas con ella, permitiendo su revisión y comparación en la secuencia. Para tanto, describimos la privatización de la Cemat y los problemas de la desestatización del sector eléctrico brasileño en su conjunto. Por fin, en la conclusión, verificamos la validad de las hipótesis e hacemos algunas consideraciones finales sobre la pesquisa.

\section{The tunnel at the end of the light: the privatization of the electric sector in Mato Grosso \\ Vinícius de Carvalho Araújo}

This article intents to analyze the formation of political and social support to state and its apparatus reform in the under national level, situated in democratic governance framework. We chose a research about the privatization of Centrais Elétricas MatoGrossenses S. A. (Cemat), regarded representative both of the reform made by the state of Mato Grosso and the difficulties of the electric sector in the national level. Its methodological framework is composed by a problem plus four work hypothesizes. It is a case study of the specie "plausibility probes" in which, through an iterative application, a theoretical statement is done and the research conclusions compared with it, allowing its revision and comparison in the sequence. For that, we decribe the Cemat privatization and the problems of Brazilian electric sector in its conjunct. In the end, at the conclusion, we verify the validity of the hypothesizes and we make some final considerations about the research. 